\title{
Current state in the research on electronic monitoring systems for the security and flow of objects and individuals
}

\author{
Marcela Man Dietrich ${ }^{1, *}$, and Marcel Sabin Popa ${ }^{2}$ \\ ${ }^{1}$ Helix Software and Engineering GmbH, Automation Engineer, 60326 Frankfurt am Main, Germany \\ ${ }^{2}$ The Technical University of Cluj-Napoca, Machine Building, 400020 Cluj-Napoca, Romania
}

\begin{abstract}
This paper sets forth the current state of security systems in prisons from Romania and around the world, particularly aiming electronic systems of monitoring the flow of people, materials control and perimeter security, focusing on the research results concluded by motion detection tests and devices. The currently used systems were observed in order to put an analysis of the methodology together and implement and perfect these systems in protected areas. The protection of citizens must be performed to the extent that is allowed by the legislation.
\end{abstract}

\section{Introduction}

As a result of a petition that I addressed to the Romanian National Administration of Penitentiaries, it was learnt that nowadays, the majority of the prison units do not have electronic systems of monitoring the flow of people. Prisons that have integrated electronic access control devices have in endowment the following: video monitoring and dispatching systems; systems with electronic access control that are based on turnstiles and personalized magnetic cards. For the control of materials placed inside the prison units, the following electronic systems are used: port metal detectors ports and handheld metal detectors; baggage scan X-ray devices.

\section{Methods of ensuring the security perimeter of premises}

To ensure the perimeter security of prisons (The figure 1 illustrates the inside area of a prison), indoor and outdoor surveillance is realized through collaboration of the following physical facilities and electronic devices [1]:

\subsection{Video surveillance subsystems}

These are made with closed circuit, and are composed of cameras installed on segments covering all due perimeter, as well as interior and exterior spaces, connected to the central command system and control type dispatch.

\footnotetext{
*Corresponding author: marcela_man@hotmail.com
} 


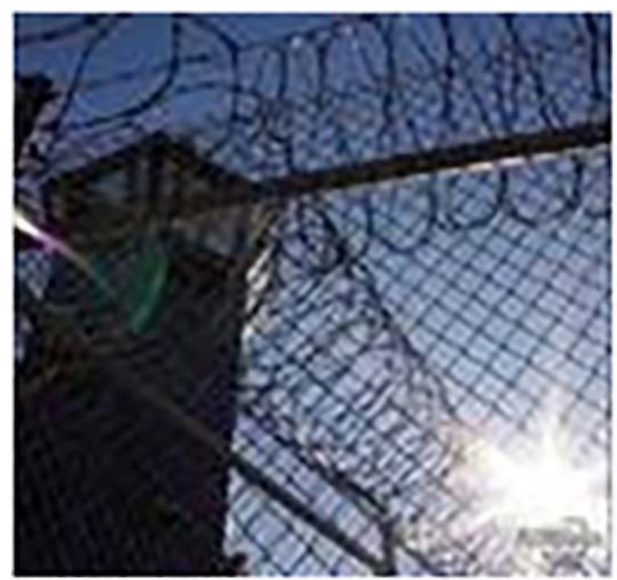

Fig. 1. Barbed wire used around the area allowed to prisoners.

On the 20th of January 2009, Romania had legalized wiretaps, recordings of SMS's and e-mails. The law was passed by the Romanian Parliament. Article 28 of the Constitution provides: "Secrecy of the letters, telegrams and other postal communications, of telephone conversations and other legal means of communication is inviolable."

\subsection{Installation for the detection of intrusion in perimeters, made of metal wires}

This installation of detection of the penetration in the perimeter is mainly against escalation or destruction of the interior fence (Fig. 1), consisting of detectors vibration and shock in yarn (sensitive burglar detectors climbing ring, cutting and deterioration) installed on the fence of metallic wires mounted on supportive poles on the inner fence that separates the forbidden area of the ownership sector.

\subsection{Protection systems with microwave beams}

These are some trespassing detection installations in exclusion zones (interior forbidden zone) by means of a beam of microwave protection. Microwaves are radio waves; whose wavelength is between $1 \mathrm{~mm}(300 \mathrm{GHz})$ and $1 \mathrm{~m}(0.3 \mathrm{GHz})$. [2] Microwave applications are of interest in relation to their propagation through the transmission lines and waveguides as well as electromagnetic resonators, instead of the conventional resonant circuit.

\section{Safety in penitentiaries}

The electronic central units, as in the central electronic unit of detected system evaluation and their transmission to the control computer and the control system computer play a big role in the security in prisons and are a main component of the running systems. 


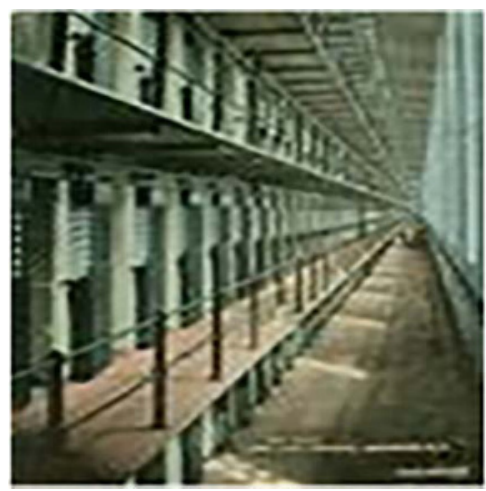

Fig. 2. The secured cells of a penitentiary.

\subsection{Security in penitentiaries}

In this chapter, an issue of interest to this article will be addressed, the current situation of the security in prisons in Romania and abroad [3]. The relevance of psychological behavior of detainees is very high, in order to implement a security system properly and analyzing existing ones.

Investigations made into the correctional environment:

- Environment in prisons:

It fluctuates, it is complex and difficult to manage within the contravention population; increasing operational requirements due to illicit drug trafficking, and the activities of band members; old infrastructure and security equipment, as per Fig. 2.

- Strategic objectives: [4]

Improving safety and security, infrastructure, capacity and operations by: a more rigorous control of entry into institutions perimeter inspection, searches and visits of offender will be under attention; detector-dog expansion teams; more thorough information security; better training of correctional officer; better equipment, better performing electronic products to support safety and security initiatives.

\subsection{Safety in prisons in case of fire}

- Monitoring the performance :

The person responsible must have procedures for employees monitoring the performance of safety systems in case of fire in their areas of control [4] [Fig.3]. European safety, health and counseling committee in case of fire through the founding the committee of staff in health and safety is responsible for the quality assurance inspections of fire safety and to identify any remedial action that may be necessary to make after an inspection. 


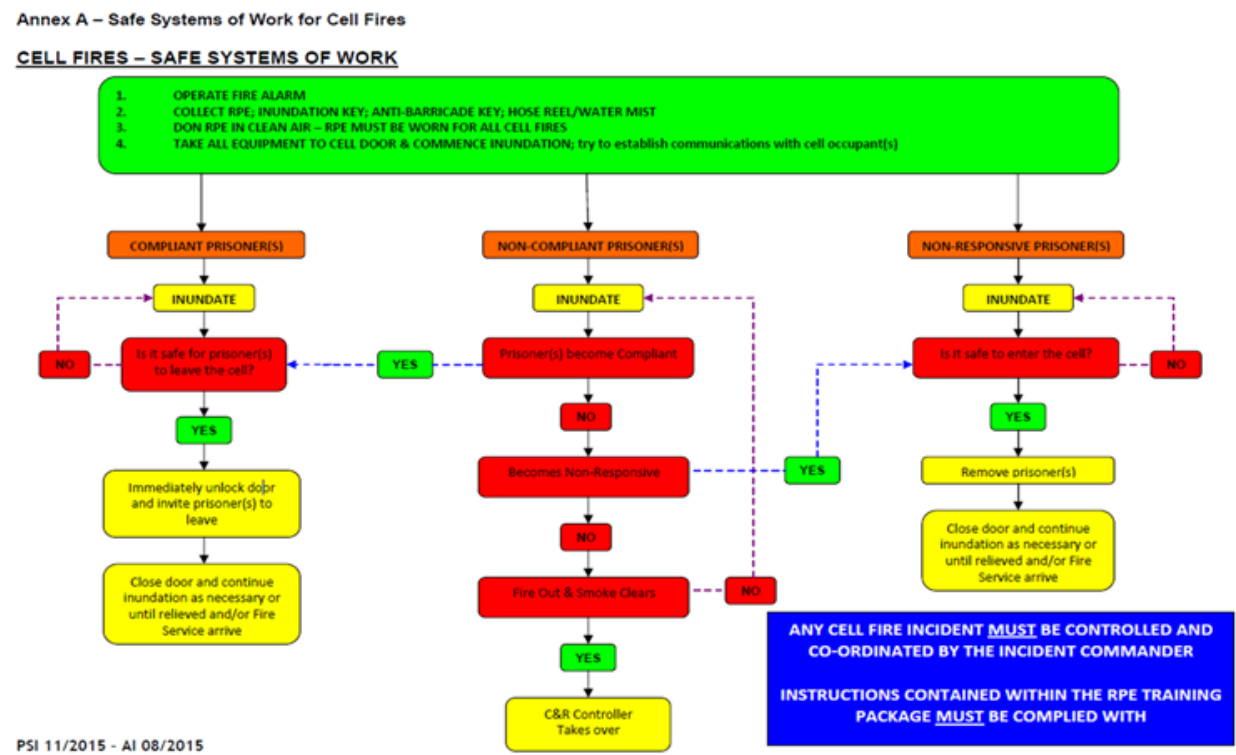

Fig. 3. The schematic cells used in the technique of reaction control in case of a fire.

\section{Motion Detection}

The research and the study of this paper is also focused on movement detection, which in the video surveillance systems is an important tool for the security of all. It warns when someone is on their own property, without authorization. The understanding of the way this technology works, helps with the configuration of the best regions for motion detection and alerts, but also officials the understanding of detection and movement.

To understand how motion detection in video surveillance systems works, we must first understand how a surveillance camera works. The current study indicated that inside the camera there is an image sensor and camera lenses directs light - when light hits the image sensor, each pixel is there for getting as much light possible. The fact that the pattern of bright and dark areas on the pixel becomes full video image is closely related to the "pictures and videos".

When configuring motion detection, select a region or area to monitor a door for example. The way it works is by comparing sequential images frame by frame of video images; if enough pixels have changed between these frames, the camera software determines something changed and will send an alert. The degree of change is determined by the level of sensitivity and level settings affect the percentage of motion detection. [5]

It depends on the level of sensitivity to changing light / dark levels of pixels. Higher sensitivity will rise to more changes while lower sensitivity will require a high level of change, such as lights occurring in a dark room. The percentage of change, on the other hand, is the percentage of pixels that have recorded a change. If the door is monitored, establishing the proportion of $50 \%$ will warn when something big enters the room, such as a person, but it ignores something smaller.

As a basic concept, the best balance in motion detection settings to prevent too many false alerts, it may take some time. During the camera configuration, the detection of someone's motion in the concerned region can be tested; the settings being adjusted as needed. It may take some time, but the effort is well worth it when notification occurs a burglary at a store or vandalizing a parking zone. Fig. 4 plots this process. 


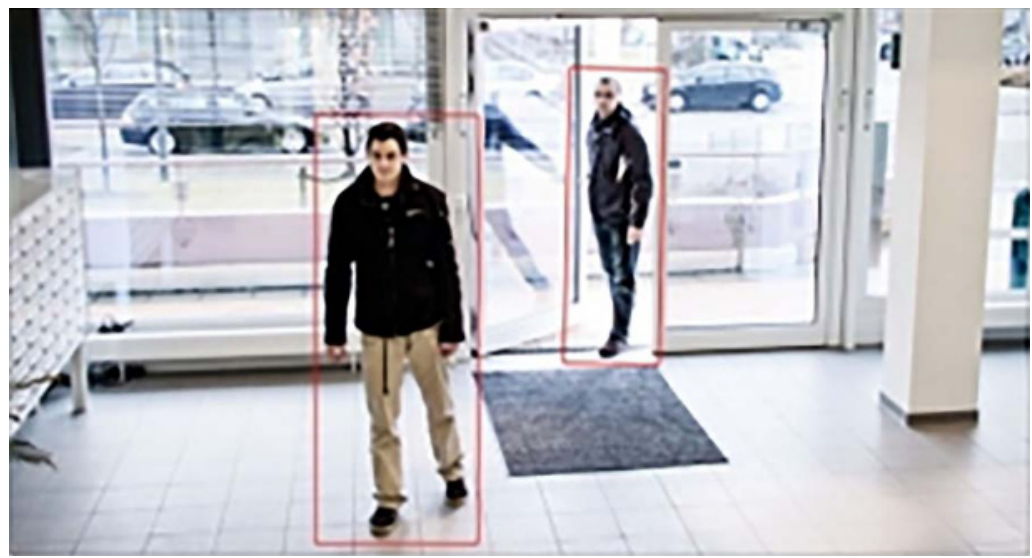

Fig. 4. Edge detection in motion [9].

\section{AVIAN - Heart Beat Detector}

A device that was deeply studied and used for this research is AVIAN [6]. Advanced interrogation and notification system for vehicles detects the presence of people hidden in them. Using data from special sensors found AVIAN shock wave generated by the beating heart (fig. 5), that plugs into any surface or object with which the body is in contact. AVIAN collects and analyses data using signal processing algorithms to detect a hidden person in less than 1 minute.

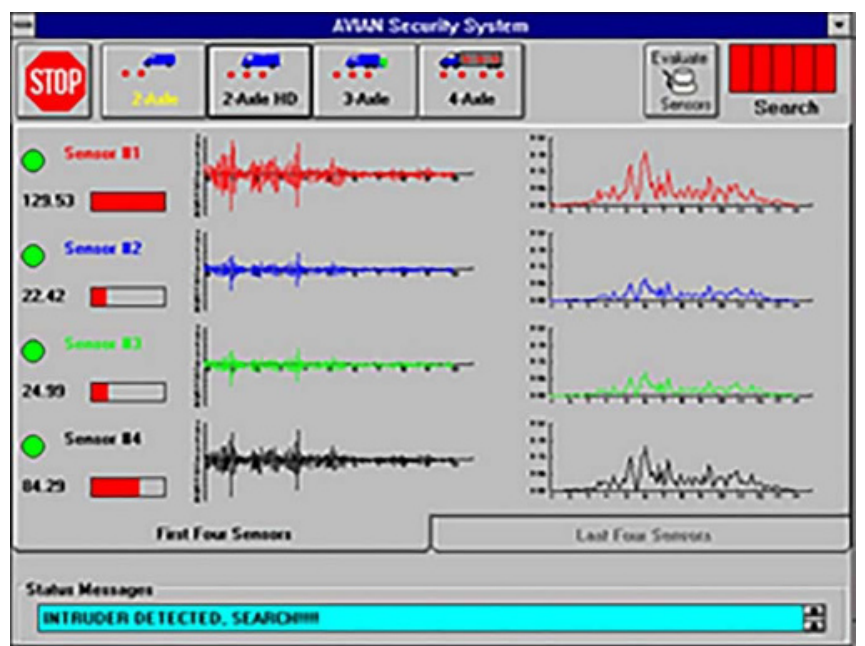

Fig. 5. The display of the Avian Heart beat detector [9].

AVIAN system consists of an industrial personal computer loaded with specially developed software, a touch-screen monitor and special sensors. The operator uses the touch screen to select the type of vehicle, the vehicle before it starts scanning. The processed data provides the operator with concrete information or evidence search.

The results of the study show that a complete search lasts less than 14 seconds from the placement of sensors on the vehicle. The system was found to be $100 \%$ effective and reliable 
in the detection of human presence in ideal conditions (strong to moderate wind protection is necessary to eliminate false positive indications). [8]

AVIAN is a cost-effective method to accurately and quickly search large or small vehicles for hidden people, regardless of content. Operation with a screen with icons makes users' training a simple matter that can be accomplished in less than an hour. The computer system doesn't need maintenance.

The cost of an Avian is less than the cost of one correction officer or servant of mobile security. It is accurate and reliable and provides the ability to quickly search the officer's fully loaded vehicle without moving or disturbing the contents of the vehicle.

\section{Conclusions}

This paper has presented the start of a research in security prison institutions, with some basic concepts, and the purpose is to implement this knowledge in the area of security systems of protected buildings. It has brought an improved classification of the monitoring systems, as well as a highlighting of the main aspects specific to the monitoring systems used in prisons. In this sense, it is to achieve a viable and applicable method to ensure the protection of persons and materials security (e.g. in case of fire, to prevent escape, or to detect weapons and illegal substances) as well as detailed analysis and deepening the current situation of the psychological part involved, as well as to compare the methods used in our country to the outside.

The possible directions of the future authors' research could be the analysis of the methodology of the placing of surveillance systems in a correctional institution, as well as a complete classification of the identified monitoring systems relevant groups and highlighting the main characteristics of each group.

This research was carried out with the support of the Technical University of ClujNapoca.

\section{References}

1. The Ministry of Justice, the Department of Homeland Security and the Penitentiary Regime, Answer ANP - following the correspondence with Marcela Man (in Romanian).

2. Associated Press (2001), Prison escape probe to focus on lax security. Retrieved January 28, 2003, http://www.clickonsa.com/ant/news/stories/news-20010108-085202.html

3. American Jail Association (1993). American Jail Association Code of Ethics, http://www.corrections.com/aja/resolutions/index.html

4. AI 08/2015, PSI 11/2015, 2015, „Fire Safety in Prison Establishments”, NOMS Agency Board

5. http://ittrends.ro/

6. Federal Bureau of Prisons (1999). Introducing AVIAN. Retrieved February 5, 2003, from http://www.heartbeat-detector-avian.com

7. www.mesa.org

8. http://www.geovox.com/

9. http://netsecurity.about.com/ 